conscience. It does so, however, on the basis of a conception of the freedom of the social individual who differs significantly from the abstract individual of traditional liberalism.

The discussion of the papers was lively, well informed and unified thematically. This highly successful occasion was an indication of the way Hegel's thought is beginning to receive its proper share of attention in British academic life. It is greatly to be hoped that the discussion will be renewed at future P.S.A. gatherings.

\title{
J. McCarney
}

Sussex University

\section{Conference of the Hegel Society of Great Britain}

The Fourth Conference of the HSGB will take place in Pembroke College, Oxford, on 15 and 16 September 1982. The proceedings will begin with tea at $4.00 \mathrm{pm}$ on Wednesday and end with tea on Thursday (in time for the beginning of the T.H. Green Centenary Conference at Balliol College, Oxford).

The theme of the HSGB Conference is Hegel's phenomenology of spirit. The following papers will be read: $\mathrm{C}$. Arthur (Sussex), 'Hegel, Feuerbach, Marx and Negativity';

R. Bernasconi (Essex), 'The Passage to Absolute spirit in the Phenomenology'; J. Hartnack (SUNY at Brockport and Aarhus University, Denmark), 'Herrschaft und Knechtschaft - an Interpretation'; L. O'sullivan (Southampton), 'Hegel and Republicanism'; D. Simpson (Edinburgh), 'Religion in the Form of Art - Hegel on the Religion of the Greek Polis'.

The charge for overnight accommodation, basic meals, tea and coffee, will be E18.00.per person. There will also be a registration fee of $E 2.00$ ( $E 1.00$ for graduate student members). It was agreed at the last Conference that, to minimize losses to the society, conference charges as well as registration fee should be paid in advance. Cheques (made payable to 'Hegel Society of Great Britain') should be sent to Dr. David Lamb, Dept. of Philosophy, The University, Manchester Ml3 9PL. 